SCOTT WELSH, MIA NOSRAT ${ }^{1}$

\title{
4. PHENOMENOLOGICAL LEARNING IN THE NORTHERN TERRITORY
}

\author{
Brill Publishers ${ }^{2}$
}

INTRODUCTION

The issue of exclusion plagues educational practices in Aboriginal communities throughout Australia. It seems that this exclusion can extend to classrooms exclusively filled with First Peoples' students. This invites a consideration of inclusion and inclusive practices regarding Indigenous education. What is inclusion? What does it mean? How might we intentionally or unintentionally include or exclude certain groups and individuals? The subject of some recent writers on the subject, such as Graham \& Slee (2008), Ballard (2006), have even implied that exclusion is implicit in the definition of inclusion. The discourse on this issue also expresses some ambivalence regarding the ethics of inclusion. Who are we including and into what? That is, for someone to be included, there must be some that are excluded, otherwise why even talk about the idea of inclusion?

A theoretical debate around the meaning and implications of the concept of inclusion flared around the early 2000s, with the invocation of Derrida and the problem for inclusion that 'a multiplicity of meanings lurk within the discourses that surround and carry it.' (Graham \& Slee 2008, p. 3) By citing inclusion as our goal, we are in a way, identifying an absence of inclusion. Indeed, the goal of inclusion implies exclusion, that we aim for inclusion suggests 'we are not there yet' and this presents a multitude of social and educational challenges that we are in such a situation regarding Australia's first peoples.

In what can perhaps be described as a more grounded manner, Ballard explores Roger and Slee's question, 'What is it that we are to be included in?' This is a question pertinent in this paper as we explore the education of Indigenous students. Would one even want to be included in a system so fraught with problems, so seemingly broken and also appearing so utterly incapable of achieving its own educational objectives?

Whilst the conventional definition of the word inclusion might be simply categorised as 'the act of including or being included in a group or structure, more recent explorations of the term conclude that:

Inclusion seems to occur when a diversity of people (e.g. of different ages, cultural backgrounds, genders) feel valued and respected, have access to opportunities and 
resources, and can contribute their perspectives and talents to improve their organisation. (Diversity Council, n.a., 2019)

And the United Nations convention on the rights of persons with disabilities

Recent Government objectives regarding Indigenous education include:

- $\quad$ increasing participation in early childhood education

- improving school attendance

- improving reading, writing and numeracy

- $\quad$ making sure students finish school.

(Indigenous Education: Closing the Gap, n.a, 20-01-2019)

These are rather humble ambitions: participation, attendance, literacy and completion. The question of completion, however, is a curious one, since social and educational theorists have directly criticised an education system that, until the 70s, funded Aboriginal people's education only until Year 9, and that this reflected social expectations or 'pre-determined stations in life' (Foley, 2018, p.132). It is perhaps important to consider these limited educational and social expectations. Furthermore, there are other factors contributing to the current historical context in which we write and describe the challenges in current education practices in the Northern Territory.

The authors of this paper are a teacher and researcher currently working in a Northern Territory school and an academic from Victoria University, concerned with the issue of inclusion. Our phenomenological research, a reflection on and analysis of experience in the forms of our original examples of reflective prose and some poetry based on encounters with a group of Indigenous students. This qualitative and somewhat creative data is used to reflect the direct experiences of the researchers and their engagement with research participants.

This chapter begins with an exploration of the struggles involved in creating educational encounters in the Northern Territory, according to the requirements of the Australian education. This chapter then describes a direct encounter or experience of learning through poetry, concluding with a successful tale of travel, pedagogy and practice-based, applied, embodied methods of education to teach a sample group of Indigenous children from the Northern Territory.

In these two encounters we see a contrast of learning styles, one in the Northern Territory involving the failure of traditional school instruction and one in Melbourne at the AFL Museum, where participatory, student-led, action-based learning saw the same students engaged and involved in a pedagogy of experience, where learning is made possible. To a large degree, the method of education used in the visit to the AFL museum follows Foley's mantra of self-education recently published in a somewhat confronting YouTube video by Professor Foley (Foley 2019). What we are proposing is that the value of an experience with the potential to educate oneself cannot be underestimated. The methods of education used at the AFL museum include kinaesthetic activities such as kicking a ball, using the technology available to practice football skills in a simulated environment, like kicking to virtual goals, then reading instructions to go to the next stage of the game. Here, learning is integrated into experience.

We will compare two moments of learning: a traditional teacher-led classroom and then a trip to a foreign land for these students who journey from remote regions to a busy city and then the MCG, where the group then engage in interactive play, embodied learning. We will advocate and explore the educational potential for this 
latter practice-based, student experience. Ultimately, we conclude that it is both a cultural necessity and a current trend in the field of education that leads to the seemingly serendipitous practice of a phenomenology of learning we describe.

\section{KEY TERMS}

PHENOMENOLOGY: In this work, we will consider phenomenology, as it is often understood, that is, as the study of structural consciousness focussing on experience of the world or things as they appear in our everyday, sensory experience (Stanford Encyclopedia of Philosophy, 2019)

Consider this recent articulation of what phenomenology is:

Phenomenology is essentially the study of lived experience or the life world (van Manen, 1997). Its emphasis is on the world as lived by a person, not the world or reality as something separate from the person (Valle, King \& Halling, 1989). This inquiry asks "What is this experience like?" as it attempts to unfold meanings as they are lived in everyday existence. (p.1)

We believe it may also be beneficial to consider the notion of hermeneutic phenomenology:

HERMENEUTIC PHENOMENOLOGY: Like phenomenology, hermeneutic phenomenology is concerned with the life world or human experience as it is lived. The focus is toward illuminating details and seemingly trivial aspects within experience that may be taken for granted in our lives, with a goal of creating meaning and achieving a sense of understanding. (Laverty 2003, p.13)

Later in this paper, we will consider personal encounters between researcher and participants reflected in poetry and personal accounts. We believe this constitutes 'hermeneutic phenomenology' by the way in which it illuminates details within the experience that may have been taken for granted and certainly the goals of our encounters are to create meaning and further understanding, empathy and relations.

INCLUSIVE PRACTICES: Inclusive practices often involve exploring new ways of teaching learners with diverse experiences, so as to expand the community of learners engaged in learning. By incorporating phenomenological learning, or what might be called direct experiential learning, into our programs, we can better accommodate our students' needs, particularly those from remote areas.

The purpose of this paper is to explore the sometimes problematic social, educational encounters and relationships that occur in Northern Territory schools between teachers and indigenous students. In terms of the notion of inclusion, we must incorporate the pain that comes with past exclusions into our understanding of what it means to foster the inclusion of particular groups traditionally excluded, such as first peoples.

What pedagogical experience seems to consist of is a social encounter, with inner and outer content directly related to the operation of the self in the social world. The self is presented in the social world which, in this instance, is an educational environment. However, the social encounter, and all it brings with it, must be considered. 
In the 'social encounter' context, the experience of the self in social reality collides with experience of the self as student. The same phenomenon can be seen in the education of Indigenous students, where the student brings with them their cultural experience and we, as educators, must attempt to embed this into the learning content and the pedagogical relationship.

Consider these observations from Hughes \& Moore (1997):

Aboriginal students have a distinctive cultural heritage whether they come from urban, rural or traditional - oriented families. The National Aboriginal Education Committee (NAEC) emphasised that teachers and schools must: " ... develop an education theory and pedagogy that takes into account Aboriginal epistemology. Only when this occurs will education for our people be a process that builds on Aboriginal and Torres Strait Islander cultures and identity.... To be effective ... skills and learning must be acquired in harmony with our own cultural values, identity and choice of lifestyle, whether we reside in an urban, traditional community or homeland centre (p.5).

The pedagogical relationship between teacher and student requires us to meet the students where they are at and the current AITSL professional standards for teachers includes addressing students' social and cultural experiences. The document speaks of opportunities for all students and specifically refers to knowing and exploring the learning styles of Aboriginal and Torres Straight Islander students (Australian Professional Standards for Teachers 2011, p. 9). Teaching and learning about Indigenous culture, conceptions of time and space, land and age, reveals to us that our students are quite often in a very different space to the one we might suppose, either directly through our own prejudices and subjective experiences and indirectly through the sometimes somewhat alienating curriculum we bring. The current Australian curriculum calls for significant social and educational action regarding this, declaring that, in seeking to know our students, we must:

Develop teaching programs that support equitable and ongoing participation of Aboriginal and Torres Strait Islander students by engaging in collaborative relationships with community representatives and parents/carers. (p.9)

In many ways, the content in our classrooms can be compared to many other social and cultural problems that have emerged out of the 200-year-or-so-long conversation between black and white cultures in this country. We don't feel we need to go into detail regarding this as it is constantly reiterated in our social and cultural lives during this period of history but perhaps we can take a moment to consider this assertion from Connell et al. regarding one aspect of the mistreatment of Aboriginal children in our society generally and in terms of education:

The many negative impacts of child removal policy on generations of Indigenous children included imparting Christian or moral doctrine rather than formal education; physical, sexual and psychological abuse; poor living standards; the substitution of many years of hard physical labour for childhood innocence and curiosity; low expectations that destroyed any possibility of the attainment of selfesteem; and poorly trained individuals with low levels of knowledge of and respect for their Indigenous culture (Beresford, 2003, p. 53). 
The classroom consists of pain in some circumstances, guilt, denial, lies and other somewhat disturbing emotions, experiences and interpretations of history, that inevitably reveal themselves through teaching and learning. Consider these words from Bunurong author and educator, Bruce Pascoe:

It wasn't because Aboriginal people lacked the ability of the Maori to fight the English, it was because they had committed their civilisation to a pan national diplomatic and intellectual pact...Let's blow away the smokescreen of self-deceit that ensured we forgot that Aboriginal Australia tilled the earth, grew grain, irrigated it, preserved perishables and siloed grain...(Pascoe, 2011, p. 9)

Sometimes the pedagogy confronts students and creates discomfort. The pedagogy can also be confronting and complex for educators. In what follows, we note the difficulties of what might be termed interculturality in education and it resonates with the ideas of Baudrillard (1998), who claims that we superimpose our political economy and obsession with accumulating goods on so-called 'primitive' cultures, where the concepts of exchange and their economic outcomes are vastly different from our own:

Where, in primitive exchange, every relationship adds to the social wealth, in our 'differential' societies every social relationship adds to individual lack, since every thing possessed is relativized in relation to others (in primitive exchange, it is valorized by the very relationship with others). (p. 67)

In what follows, we will provide examples from a journal, documenting our experiences teaching in the Northern Territory. How do these reflections conform with this idea of learning as an inner experience, akin to Laing's (1967) conception of the unconscious,

The condition of alienation, of being asleep, of being unconscious, of being out of one's mind, is the condition of the normal man. Society highly values its normal man. It educates children to lose themselves and to become absurd, and thus to be normal. Normal men have killed perhaps 100,000,000 of their fellow normal men in the last fifty years. (p.10)

Issues around normality seem important to understanding what education is in different social and experiential contexts, particularly those of our students in this study:

Growing up in violent families, going through death and griefs, constant fighting in the community, drug and alcohol disorders at birth and so many other issues that would've impacted the development of their brains.

Why insist of delivering Australian Curriculum to these innocent children who did not choose to have their brains not developed; however, are unfortunate enough to go through traumatic life experiences? I can't help, but wonder...

I am feeling frustrated. I feel as though I am setting my students up for failure. The curriculum is letting them down and I am not doing anything about it. Why am I writing my thesis about Indigenous education when I can't even implement 
change within my classroom? This is so much more complicated that I thought it'd be... I feel like giving up...

This testimony is sourced from the journal of the co-author of this article, a teacher working in a remote area of the Northern Territory. What we can understand through this work is that the phenomenology of teaching can be just as troubling as that of learning and both can take place in the silence of Laing's unconscious, in what we do not say, or hear, in the silences that permeate every noisy, sometimes violent classroom. Whilst the connection between an Australian classroom educating First Peoples and a Scotttish psychiatrist may not be immediately apparent, this needs to be considered in terms of the "madness" of the social situation in both the classroom, the context of our study, and the 'disturbed family' (Laing 1968). The following observation was recorded in the teacher's journal:

I was teaching report writing in the morning and I was holding a picture of a fish up in front of a group of students. I asked: "What does the fish look like?". "Full stop?", someone called out!!!! “Capital letter?”, said another student!!!!! The answers they were giving me had nothing to the with my question. I couldn't stop thinking about the fact that there's so much happening around them that are not being processed by their little brains and these are the most common sentences they are constantly hearing: "Make sure you start your sentence with a capital letter, don't forget full stops at the end"! They know it's the writing lesson, so they are throwing whatever they can remember at me, hoping they might have the right answer! My heart sinks; thinking about how the curriculum is failing these students on a daily-basis, not recognising their very specific needs. My principal and school feel very obligated to deliver the curriculum and I just cannot find the relevancy to these beautiful, yet lost (in learning), students.

What observations can we make about language here? Clearly, we are speaking at least two, possibly three, different languages. Or, perhaps more appropriately, we are simultaneously in two or three conversational realities. We are the teacher in the testimonial data and we are speaking one language, the students another and, as we observe the principal, yet another. We could take this still further and suggest that the school and the curriculum are speaking yet another language. Take this comment on RD Laing:

Laing was revolutionary in valuing the content of psychotic behaviour and speech as a valid expression of distress, albeit wrapped in an enigmatic language of personal symbolism which is meaningful only from within their situation.

Like Laing, we ought to always attempt to interpret any transgressive behaviour of this country's first peoples and children in the historical context in which we live, in other words, according to what Mills called the sociological imagination:

The sociological imagination enables its possessor to understand the larger historical scene in terms of its meaning for the inner life and the external career of a variety of individuals (Mills 1959).

Whilst the historical context of Australia's first people's experience may not always be at the bottom of one's experience in the world, it at least deserves consideration, as some behaviours may be 'a valid expression of distress...meaningful only from within their situation.' 


\section{NORMALITY IN THE SHADOW OF GENOCIDE}

What we call 'normal' is a product of repression, denial, splitting, projection, introjection and other forms of destructive action on experience. It is radically estranged from the structure of being. The more one sees this, the more senseless it is to continue with generalized descriptions of supposedly specifically schizoid, schizophrenic, hysterical 'mechanisms.' There are forms of alienation that are relatively strange to statistically 'normal' forms of alienation. The 'normally' alienated person, by reason of the fact that he acts more or less like everyone else, is taken to be sane. Other forms of alienation that are out of step with the prevailing state of alienation are those that are labelled by the 'formal' majority as bad or mad. (Laing, 1967, p. 10)

There is a tone of utter despair in the testimony, of complete hopelessness at the alienation experienced by the children who confuse a fish for a full stop. Like Laing's schizoid, the aboriginal students have 'depersonalised their relationship with themselves' through their experience of Western book learning. I believe that this phenomenon could be described as a form of social madness, the kind of which Laing speaks, it is a type of madness that manifests itself in groups and belongs to the group context. It does not exist on its own in one individual.

The glare of his awareness kills his spontaneity, his freshness; it destroys all joy. (p. 112)

Or this:

We are now in a position to suggest that whereas he is afraid not to be dead and lifeless...he dreads real aliveness. (p.113)

\section{THE FLIP-SIDE OF PHENOMENOLOGICAL LEARNING}

How do we speak of pain? How do we express guilt? What about the dark-side of our cultural heritage? For a long time, the pain of Australia's first peoples remained unexpressed, certainly excluded from the historical narratives that form the foundations of this country. The concept of 'intersectional discrimination', utilised by contemporary authors on the subject of First Peoples' dispossession and pain, such as Scott Avery (2016) claims that this occurs when people are discriminated against in relation to multiple aspects of their identity. For example, race and disability.

The historical silence on the issue is considered in a recent article in The Conversation, citing the historically significant lectures of W.E Stanner:

Stanner argued that Australia's sense of its past, its very collective memory, had been built on a state of forgetting, which couldn't "be explained by absentmindedness":

It is a structural matter, a view from a window which has been carefully placed to exclude a whole quadrant of the landscape. What may well have begun as a simple forgetting of other possible views turned under habit and over time into something like a cult of forgetfulness practised on a national scale. 
For a time, Stanner's writings led to the establishment of an entire discourse that has continued, despite various political interruptions. It is perhaps somewhat tragic and certainly terrifying that the narrative of history can be guided by the pragmatic and immediate term politics of the time. The apology and recognition of black suffering is a prime example of this and the ongoing intellectual war has been deeply personal and at times brutal. From John Howard's denial of the genocide of Australia's first peoples to intellectuals, such as Caroline Beasley, overtly attempting to break the 'great Australian silence' (Beasley, 2014).

In the early 1970s historians began to write 'social history', which saw invasion as the main theme of colonisation, as opposed to the previously 'peaceful' arrival of the British that underscored traditional colonial history. The perceived incompatibility between Indigenous and European cultures was clear, especially surrounding land use, and there was an understanding that violence on the frontier had caused the British destruction of Indigenous societies. (Beasley, 2014, p.4)

According to Beasley, then, we are half a century into the process of writing the social history around the theme of colonisation as invasion. Inherent in this ongoing task is an insight into the physical, emotional, psychological and social pain of those who experienced this attempted genocide and dispossession. The necessity to express this and other traumatic aspects to this multi-faceted, disturbing "social history" seems to require the language of poetry. This is a practice so common in Jewish Holocaust history that it has become an accepted pedagogical method for students to learn about that particular attempted genocide. This, and Scarry's (1997) work on the inexpressibility of pain invites the form of poetry into this moment of historical precarity, not only for the victims of the attempted genocide but also for those of us attempting to understand what happened and how we can incorporate it into our understanding of a real social history.

In our exploration of the fragmented, deliberately forgotten, ignored or denied histories of this land's first peoples, we need to explore ways of rehumanising those who have been dehumanised by the historical narratives written until now. One way of rehumanising and exploring our own experiences, as we encounter the facts of this history and our position in it, might be through poetry. For it is impossible for me to engage in educating Aboriginal students without considering the facts of this relatively new historical narrative. This is apparent from the earlier example, where there appeared to be a complete disconnect in the conversation between the educator and the students. It was as if we were speaking a foreign language and perhaps we are because disability in Aboriginal and Torres Strait Islander culture does not need to come from a place of deficit. However, perhaps due to the Government requirements referred to throughout this paper and in the teacher's journal reflections, we think in terms of deficit.

\section{EXPERIENTIAL LEARNING \& UNDERSTANDING THROUGH POETRY}

Consider this simple definition of phenomenological learning from the Encyclopedia of the sciences of Learning:

Basically, learning can be characterized as an ability to revise existing patterns of feeling, thinking, and acting while intentionally accommodating changes and developing new competencies and orientations. For this, processes of learning cannot merely be reduced to distinct knowledge of contents or outcomes of learning, 
but comprise and alter the entire learning situation. Accordingly, learning can be defined as an embodied, emotional, cognitive and responsive, individual and/or collective. (Seele 2012, p.1)

In light of the troubling experience of non-learning in the classroom, the teacher, one of the authors of this chapter, concocted an idea to take these students from a remote area of the Northern Territory and show them the city of Melbourne. Included in the trip was a visit to the MCG, a known home of AFL football. The students were given a tour of the entire stadium, including the AFL museum. This interactive, state of the art contemporary educational facility inspired these young students and the encounter with one of the authors of this chapter is documented in a poem that follows.

It is a valid question to raise as to the reason for a poem being included in this chapter on inclusive education. My thesis is this: there are long-standing, underlying, historical and ethical difficulties involved in the task of both educating Aboriginal and Torres Strait Islanders(?) and also the act of writing about the process. We are entering a context, both real and imagined, where the teacher plays the role of invader, at least on some level, and the student is the innocent victim. Whilst this may not necessarily be real for any of the participants, it is nonetheless real in terms of the cultural, or at least historical, context of the encounter.

With this in mind, we have presented an account of the encounter at the museum in the form of poetry:

\section{BLACK KIDS}

They moved like the earth, Slowly, called me mister,

Doctor, I muttered under

My breath, I am sure

They didn't hear

They were moving

Through Melbourne

Like one, with each

Other and held the

Hands of those they

Trusted along the way

And offered to tie

My shoe-laces

I said 'No.'

I will not let you

Tie my in-

competent shoe

I want to hear you

Philosophise

I want to know

The world through your eyes..

Someone else can tie

Our shoes.

And they took my arm 
And comforted me some

And made themselves part

Of me and me part of them

To my own new discomfort

It's a modern Western thing

And I was constantly reminded

That they had been here

Forever and we still at Pine

Creek. Though they were

Here and maybe I was there

Anyway, it was there

Like Laing's unconscious,

Absolutely everything else,

The wasn't perhaps was,

And I know they'd think

Me mad for saying such

Things but this is the truth

They gave me silently

Without wanting even

A nod in return,

And they were like that

In the football museum

Too. No ego

In their

Ambition to

Put the ball

In the hole.

In the first half of this paper, we focused on the alienating aspects of education in the Northern Territory. We have, in a sense, conceded and reflected on our failings, as individuals and as a fragmented and troubled culture in Australia in the $21^{\text {st }}$ century. In the process we examined a moment of 'non-learning', a failure to learn. Consider this recent consideration of what learning is:

In human beings, learning primarily takes place through the brain and the central nervous system, which are specialised parts of the body, and if one wishes to approach an understanding of the way in which our learning potential has developed and functions, one must go beyond the division between body and psyche, between the bodily and the mental, which has been so central in the understanding of the Western world for centuries. (Illeris 2007)

In the second half of this paper, we explored a second example of learning that represents a positive encounter with education and speaks directly to ways of learning that are practice-led and student-based and are ideal for all students, including indigenous students. The confrontation with interculturality is inevitable and is embodied in the subjectivity of the poem. The persona of the poem attempts to grasp the experience of the group of students he encounters, sometimes seeming to objectify them, but always in an attempt to understand not only the individual 
encounter documented here but also the ever-changing historical and social context in which it occurs.

Whilst acknowledging deeply embedded problems around "perspective consciousness", which, 'in simple terms refers to the recognition that perspectives are different from opinions since perspectives are the outcome of a complex interplay of the contexts of our lives' (Amthor \& Heilman, 2010, p. 147). It is associated with the unique experiences of a particular social or cultural group. A contemporary New York private school, Hewitt (n.a. 2010)) also expresses an optimism in the recognition of particular cultural groups' unique experiences. By tailoring learning around this 'peculiarity, we can counteract some of the negative and unproductive experiences of non-learning found in the first half of this paper. The "contrasting world view and ontology", as well as experiences of the students, is identified in the practice-based approach of learning through a visit to the AFL museum, for example. The incorporation of what Hewitt calls the interactional/transactional saw a marked difference in the students' engagement and there appears to be potential for further learning in this area.

This approach not only provides a way of teaching and learning for Indigenous students, it also has the potential to contribute to the process of reconciliation through learning. By accommodating and incorporating Indigenous perspectives and approaches to education, we acknowledge that the conventional "white" approach to education is neither superior nor always successful. This opens up new possibilities for how we might incorporate practice-based, experience-led into conventional classrooms and utilise them to turn negative learning encounters into positive, fulfilling pedagogical experiences inside and outside classrooms. 


\section{REFERENCES}

Amthor, R. F., \& Heilman, E (Eds.). (2010). Perspective Consciousness about Identity, Power, and Culture. Social studies and diversity education: What we do and why we do it. Taylor \& Francis

Australian Professional Standards for Teachers (2011). n.a, Australia Institute for Learning and School Leadership. https://www.aitsl.edu.au/docs/default-source/apstresources/australian_professional_standard_for_teachers_final.pdf accessed online 2-06-2019.

Avery, S (2016). Intersectional Dimensions on the Right to Health for Indigenous Peoples. First People's Disability Network, Australia.

Ballard, K (2006). Researching disability and inclusive education: participation, construction and interpretation. International Journal of Inclusive Education, Vol 1, 1997-Iss 3.

Beasley, C (2014). The Breaking of the 'Great Australian Silence: How and Why the Writing of Indigenous Australian History has Changed over the Last 40 Years. ANU Press, The Australian National University, Canberra, Australia.

Diversity Council, n.a. (2019) https://www.dca.org.au/topics/inclusion, accessed online 16-02-2019.

Beresford,

Foley, D (2003). An examination of Indigenous Australian entrepreneurs. Journal of Developmental Entrepreneurship, 8(2):133-151, Canberra, Australia.

Foley, D (2019). https://www.youtube.com/watch?v=Iw8YVBbQgNg, accessed online 29-05-2019.

Graham, L, \& Slee, R (2008). An illusory interiority: interrogating the discourse/s of inclusion, Educational Philosophy and Theory 40(2):277-293, London, United Kingdom.

Hewitt School, n.a., https://www.hewittschool.org/student-life/diversity-inclusivity, accessed online 28-01-2019.

Indigenous Education, Teaching and Learning, https://www.education.gov.au/indigenous-schooling, n.a., accessed online, 20-012019.

Hughes \& More (1997). Aboriginal Ways of Learning \& Learning Styles, Paper presented at the Annual Conference of the Australian Association for Research in Education Brisbane, December 4, 1997.

Illeris, K (2007). How we Learn: Learning and Non-Learning in School and Beyond, Routlege London \& New York.

Laing, RD (1961). Self \& Others: Collected Works of RD Laing, Tavistock Publications Ltd, New York.

Laing, R. D. (1990). The politics of experience and the bird of paradise. Penguin UK.

Laverty, S (2003). Hermeneutic Phenomenology and Phenomenology: A Comparison of Historical and Methodological Considerations,International Journal of Qualitative Methods, University of Alberta, International Institute for Qualitative Methodology, Alberta: USA.

Pascoe, B (2011). Dark Emu, Allen \& Unwin.

Scarry, E. (1987). The body in pain: The making and unmaking of the world. Oxford University Press, USA. 
Seel, M (2012). Encyclopedia of the Sciences of Learning, SpringerLink.

Smith, E (2006). The Body in Pain: An Interview with Elaine Scarry', Concentric: Literary and Cultural Studies 32.2 September 2006: 223-37

Stanford

Encyclopedia

of

Philosophy, https://plato.stanford.edu/entries/phenomenology/, n.a., accessed online,20-012019.

Valle, S, King, M \& Halling, S (1989). An Introduction to ExistentialPhenomenological Thought in Psychology, Existential Phenomenological Perspectives in Psychology: Exploring the Breadth of Human Experience, Plenum Press: London. 
NOTES 